\title{
Fenotipo "killer" en levaduras productoras de etanol aisladas de chicha de jora del distrito de Moche, región La Libertad, Perú
}

Phenotype "killer" in ethanol producing yeasts isolated from chicha Moche District, La Libertad región, Perù

${ }^{1}$ Cristian Polo Z. ${ }^{\text {a }}{ }^{1}$ Juan Pedro H., ${ }^{\text {11 Juan Díaz O }}$. y ${ }^{2}$ Marcia Fernández C .

\section{RESUMEN}

Se determinó el porcentaje del fenotipo "killer" en levaduras productoras de etanol aisladas de chicha de jora del distrito de Moche, región La Libertad, Perú, elaboradas en forma artesanal. Para ello se recolectaron muestras de chicha de la Campiña y del Pueblo de Moche, y a partir de ellas se aislaron 60 cultivos de levadura utilizando Agar Sabouraud. Los cultivos fueron reactivados en Agar Extracto de Malta y luego se les realizó la detección de la actividad "killer" en Agar Yeast Peptone Dextrose tamponado con Buffer Acetato a pH 5,6; se utilizaron los cultivos de Saccharomyces cerevisiae CECT 1387 y Saccharomyces cerevisiae CECT 1443 como cepas patrón. Después de la detección de dicha actividad se halló la presencia de los fenotipos "killer", "neutro" y "sensible"; además de la coexistencia de fenotipos compatibles en una misma muestra de chicha de jora. El fenotipo "killer" representó el $31 \%$ de los cultivos, mientras que los fenotipos "neutro" y "sensible" representaron el $47 \%$ y $21 \%$ respectivamente.

Palabras clave: Levadura, Saccharomyces cerevisiae, fenotipo, killer, chicha.

\section{ABSTRACT}

This research aimed to determine the percentage of phenotype "killer" in ethanol producing yeasts isolated from chicha Moche District, La Libertad region, Peru, prepared in the traditional way. This chicha samples of the countryside and the "Pueblo de Moche", and from them were collected 60 yeast cultures were isolated using Sabouraud Agar. The cultures were reactivated in Malt Extract Agar and then underwent screening activity "killer" on Yeast Peptone Dextrose Agar buffered whit Acetate Buffer to pH 5.6; Saccharomyces cerevisiae strains CECT 1387 and CECT 1443 were used as standards. After detecting the presence of said activity phenotypes "killer", "neutral" and "sensitive" was found; well as the coexistence of compatible phenotypes in the same sample of chicha. The phenotype "killer" accounted for $31 \%$ of the cultures, while "neutral" and "sensitive" phenotypes accounted for $47 \%$ and $21 \%$ respectively.

Keywords: Yeast, Saccharomyces cerevisiae, phenotype, killer, chicha.

\footnotetext{
${ }^{1}$ Universidad Nacional de Jaén. Cajamarca, Perú.

${ }^{2}$ Instituto de Educación Superior Pedagógico Público "Víctor Andrés Belaunde” de Jaén. Cajamarca, Perú.

${ }^{a}$ Biólogo - Microbiólogo. ${ }^{b}$ Biólogo. ${ }^{\mathrm{c}}$ Licenciado en Estadística. ${ }^{\mathrm{d}}$ Estudiante.
} 


\section{INTRODUCCIÓN}

Las levaduras se hallan ampliamente distribuidas en el medio ambiente, en el suelo de los viñedos, sobre la piel de algunas frutas, en la superficie de los vegetales, en el aparato digestivo de los animales (Lee,2000). La microflora natural de los frutos ricos en azúcares fermentables está compuesta fundamentalmente por mohos $\mathrm{y}$ en menor número por bacterias $\mathrm{y}$ levaduras, y varía con el clima y tipo de suelo; hay una gran variabilidad de los tipos microbianos encontrados en la flora natural de los frutos procedente de una región a otra (Bourgeois y Larpent, 1995).

La transformación del mosto es consecuencia de un complejo conjunto de reacciones bioquímicas, producidas por distintas especies de levaduras y bacterias lácticas. Las levaduras son responsables de la biotransformación de los azúcares, principalmente glucosa y fructosa, en alcohol y $\mathrm{CO}_{2}$ (Pretorius, 2000). Desde Pasteur hasta la fecha se han realizado muchos estudios sobre fermentación alcohólica; sin embargo, debido a la complejidad de las reacciones químicas que se generan es un proceso aún no entendido completamente (Ribéreau-Gayon, y otros, 1975) y(Lafon - Lafourcade, 1983).

Sobre el origen de las levaduras existen dos teorías. La primera sostiene que los frutos dañados sirven de "depósito" para microorganismos, entre los que se incluye Saccharomyces cerevisiae, y que por tanto, se desarrollan en las fermentaciones espontáneas (Mortimer y Polsinelli, 1999). La segunda teoría afirma que proceden de las bombas, tuberías, depósitos de fermentación y de la bodega; aunque no se descarta una presencia minoritaria de $S$. cerevisiae en los frutos
(Martini,1993), (Fleet y Heard, 1993) y (Vaughan-Martini y Martini, 1995).

Durante la selección natural en una fermentación espontánea, se generan interacciones levadura-levadura de tipo antagónico; esa interacción denominada fenómeno "killer" fue descubierta en 1963 por Bevan y Makower (Radler, 1980), (Shimizu, 1993) y (Nguyen y Panon, 1998). Implica la secreción por parte de ciertas levaduras de una proteína tóxica de bajo peso molecular denominada toxina "killer" (Wickner, 1996) y (Woods y Bevan, 1968). Este fenómeno ha sido observado en Saccharomyces, Debaryomyces, Pichia, Zygosaccharomyces, Hanseniaspora, Candida y Cryptococcus (G. Fleet, 1997). La distribución del fenotipo "killer" varía en función de la zona y su frecuencia de aislamiento es relativamente baja (Angulo y col, 1993), (Hidalgo y Flores, 1994).

Las levaduras que producen la toxina "killer" son inmunes a dicha toxina, pero tienen la capacidad de ser letales para las células denominadas sensibles, las cuales pueden ser del mismo o de diferente género; existen además cepas neutras que no producen dicha toxina ni son sensibles a ella (Woods y Bevan, 1968), (Wickner, 1996) y (Epifanio, 2005). Existen por lo tanto, tres fenotipos "killer": killer $\left(\mathrm{K}^{+} \mathrm{R}^{+}\right)$, sensible $\left(K^{-} R^{-}\right)$y neutro $\left(K^{-} R^{+}\right)$(Epifanio, 2005).

La chicha de jora es un producto oriundo del Perú con más de 3000 años de antigüedad, que se elabora artesanalmente y se consume además en otros países de América del Sur, constituyendo un producto potencialmente industrializable. Se denomina chicha de jora, a la bebida alcohólica obtenida por fermentación de la materia azucarada contenida en el mosto de malta de maíz (Vásquez, 1979). 
Debido a que en el Perú no existen estudios publicados sobre la distribución del fenotipo "killer" en levaduras aisladas de chicha de jora, la presente investigación se enfoca en solucionar esta falta de conocimiento determinando el porcentaje del fenotipo "killer" en levaduras productoras de etanol aisladas de chicha de jora del distrito de Moche tanto de la campiña como del pueblo de dicho distrito, región La Libertad, Perú, elaboradas en forma artesanal.

\section{MATERIALES Y MÉTODOS}

\section{Materiales}

\section{Material biológico}

Muestras de chicha de jora elaboradas en la campiña y en el pueblo de Moche.

Dos cultivos patrones de Saccharomyces cerevisiae, CECT" 1387 con fenotipo "killer" y $\mathrm{CECT}^{*} 1443$ con fenotipo "sensible". CECT": Colección Española de Cultivos Tipo.

\section{Medios de cultivo y reactivos}

Agar Extracto de Malta-AEM.

Agar Sabouraud-AS.

Agar Yeast Peptone Dextrose-YPD, tamponado a pH 5,6.

\section{Buffer Acetato a pH 5,6.}

\section{Métodos}

\section{Recolección de muestras de chicha de jora}

Las muestras de chicha de jora, producidas en forma artesanal, fueron recolectadas en el distrito de Moche, el cual comprende a la Campiña y el pueblo de Moche. Luego, fueron transportadas al Laboratorio de Microbiología Industrial para su posterior procesamiento.

\section{Aislamiento de levaduras}

Las muestras de chicha de jora fueron sembradas por estría sobre placas con AS y luego fueron incubadas entre $20{ }^{\circ} \mathrm{C}$ a $22{ }^{\circ} \mathrm{C}$ por 48 horas. Posteriormente se realizaron coloraciones de Gram para las colonias aisladas y se verificó tanto la forma levaduriforme como la pureza de las mismas. Las colonias que presentaron estas características fueron repicadas en frascos conteniendo AS e incubadas entre $20{ }^{\circ} \mathrm{C}$ a $22^{\circ} \mathrm{C}$ por 24 horas para obtener cultivos puros de levadura, los cuales fueron conservadas en refrigeración a $8^{\circ} \mathrm{C}$.

\section{Reactivación y evaluación de la pureza de los cultivos de levadura}

Los cultivos de levadura conservados en AS, fueron sembrados en frascos conteniendo AEM; luego fueron incubados entre $20{ }^{\circ} \mathrm{C}$ a $22{ }^{\circ} \mathrm{C}$ por 24 a 48 horas; cumplido el tiempo de incubación, se hicieron coloraciones de Gram para determinar su pureza. Los cultivos puros fueron conservados en refrigeración a $8{ }^{\circ} \mathrm{C}$, y los que estuvieron contaminados se purificaron mediante diluciones en agua destilada estéril y siembra en AS.

\section{Detección de actividad "killer", "neutra" ó "sensible"}

Para evaluar el fenotipo "killer" de las levaduras productoras de etanol, estas fueron sembradas por estría en placas conteniendo agar YPD, tamponado con buffer acetato a $\mathrm{pH}$ 5,6 y fueron incubadas por 10 días a $22{ }^{\circ} \mathrm{C}$. Luego fueron sembradas junto a las estrías anteriores el cultivo S. cerevisiae CECT 1443 con fenotipo "sensible" y fueron incubadas por 48 horas a 22 ${ }^{\circ} \mathrm{C}$. Las levaduras que inhibieron el crecimiento del cultivo de $S$. cerevisiae CECT 1443 fueron consideradas con fenotipo "killer". 
Para evaluar el fenotipo "neutro" ó "sensible" fueron sembradas por estría el cultivo $S$. cerevisiae CECT 1387 con fenotipo "killer" en placas conteniendo agar YPD, tamponado con buffer acetato a $\mathrm{pH}$ 5,6 y fueron incubadas por 10 días a $22{ }^{\circ} \mathrm{C}$. Luego fueron sembradas junto a dichas estrías las levaduras productoras de etanol que no inhibieron el crecimiento del cultivo de $S$. cerevisiae CECT 1443 en la evaluación del fenotipo "killer" y fueron incubadas por 48 horas a $22^{\circ} \mathrm{C}$. Las levaduras que desarrollaron fueron consideradas con fenotipo "neutro" y las que no desarrollaron fueron consideradas con fenotipo "sensible".

\section{RESULTADOS}

Se aislaron 60 cultivos de levaduras productoras de etanol a partir de muestras de chicha de jora del distrito de Moche, región La Libertad, Perú. De los 60 cultivos se observaron diferentes porcentajes de fenotipos "killer", "neutro" y "sensible" (Figura 1).

Las levaduras aisladas de la Campiña de Moche presentaron predominio del fenotipo "neutro" (50\%), mientras que el fenotipo "killer" y "sensible" representó el 30\% y 20\% respectivamente de un total de 30 cultivos (Figura 2).

Las levaduras aisladas del pueblo de Moche presentaron predominio del fenotipo "neutro" (44\%), mientras que el fenotipo "killer" y “sensible" representó el 33\% y 23\% respectivamente de un total de 30 cultivos (Figura 3).

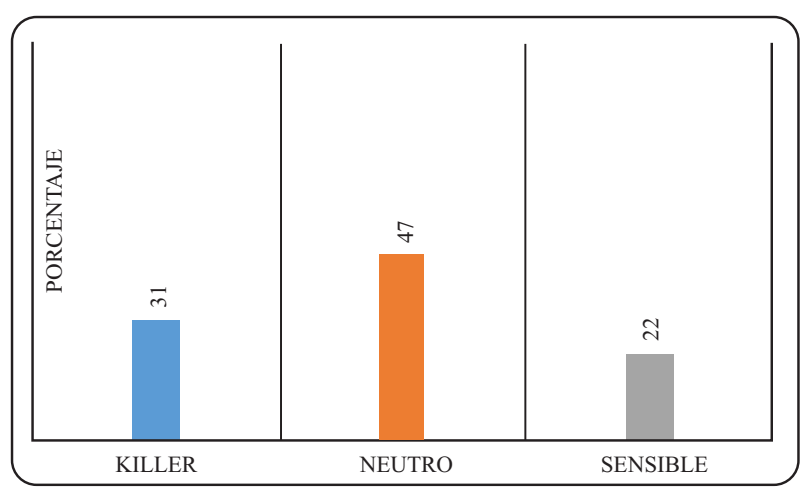

Figura 1. Porcentaje de los fenotipos "killer", "neutro" y "sensible" de las levaduras productoras de etanol aisladas de chicha de jora del distrito de Moche.

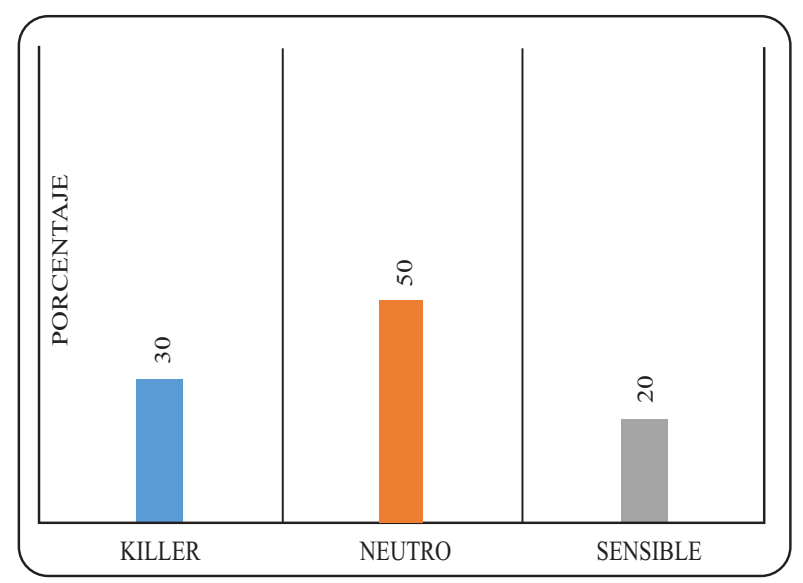

Figura 2. Porcentaje de los fenotipos "killer", "neutro" y "sensible" de las levaduras productoras de etanol aisladas de chicha de jora de la campiña de Moche.

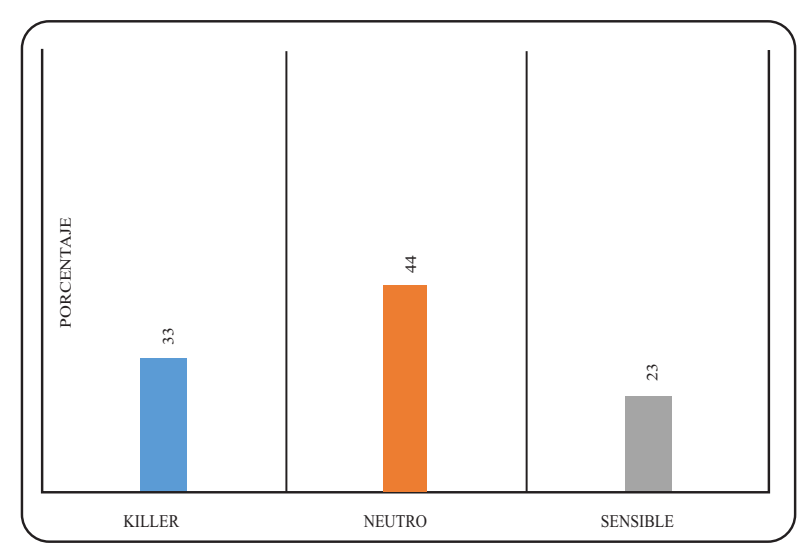

Figura 3. Porcentaje de los fenotipos "killer", "neutro" y "sensible" de las levaduras productoras de etanol aisladas de chicha de jora del pueblo de Moche. 


\section{DISCUSIÓN}

La presente investigación nos proporciona los primeros resultados de los fenotipos "killer", "neutro" o "sensible" de 60 cultivos de levaduras productoras de etanol aisladas de chicha de jora procedente de la campiña y pueblo del distrito de Moche (ambos en la región La Libertad, Perú). Sobre la base de los resultados se encontró predominio de levaduras con fenotipo "neutro" que representaron el $47 \%$ de los aislamientos, esto concuerda con Van Vuuren y Jacobs (1992) quien hallò que en las poblaciones de Saccharomyces salvajes puede existir un número relativamente elevado de cepas con fenotipo "neutro". Además, los fenotipos "killer" y "sensible" representaron el $31 \%$ y $22 \%$ respectivamente.

El porcentaje hallado para el fenotipo "killer" en esta investigación es contrario a lo hallado por Angulo et al. (1993) e Hidalgo y Flores (1994) quienes determinaron que la frecuencia de aislamiento para este fenotipo es relativamente baja. Asimismo, el porcentaje hallado para el fenotipo "sensible" es contrario a lo hallado por Rodríguez et al. (1998) quienes investigaron el fenotipo "killer" de 404 cepas de la especie $S$. cerevisiae pertenecientes a las comarcas vitivinícolas de A Ribeira Sacra Ourensana y O Ribeiro (ambas en Ourense, España), encontrando que las cepas "sensibles" dominaron ampliamente y representaron cerca del $90 \%$ del total de los aislamientos, lo que concordó con resultados obtenidos por Fleet y Heard (1993), Farris et al. (1991), Angulo et al. (1993) e Hidalgo y Flores (1994) en diferentes zonas vitivinícolas. Sin embargo, los estudios de Bourgeois y Larpent (1995) indican que hay una gran variabilidad de los tipos microbianos encontrados en la flora natural de los frutos procedentes de una región a otra.

En esta investigación se halló que el 30\% de los cultivos de levaduras aisladas de chicha de jora de la Campiña de Moche presentaron fenotipo "killer", mientras que el mismo fenotipo representó el 33\% de los cultivos de levaduras aisladas de chicha de jora del pueblo de Moche. Esto nos indica que a pesar de las diferencias micro-geográficas existentes en estos lugares el fenotipo "killer" se halló ampliamente distribuido, en contraste con los resultados obtenidos por Rodríguez et al. (1998) y Lema (1995) quienes hallaron bajos porcentajes para este fenotipo.

Los estudios de Rodríguez et al. (1998) indican que el $8 \%$ de las cepas aisladas en A Ribeira Sacra Ourensana y el $26 \%$ de las cepas procedentes de $\mathrm{O}$ Ribeiro mostraron actividad "killer". Esto se relaciona con los resultados obtenidos por Cansado et al. (1992) donde encontraron porcentajes similares en la comarca de O Ribeiro. Por el contrario, Lema (1995) encontró que en la comarca vitivinícola de $\mathrm{O}$ Baixo Miño el 11\% de las cepas mostraron actividad "killer". Según Rodríguez et al. (1998), estas diferencias podrían relacionarse con las particulares condiciones micro geográficas de cada comarca como también lo proponen Farris et al. (1991), Angulo et al. (1993) e Hidalgo y Flores (1994).

En esta investigación se encontró que en algunas muestras de chicha de jora coexistían levaduras con fenotipo "killer" y "neutro", en otras coexistían levaduras con fenotipo "neutro" y "sensible" y también se encontró que algunas 
muestras presentaban un solo fenotipo mencionado.

La coexistencia entre las levaduras con fenotipo "killer" y "neutro" se explica debido a que ambas levaduras toleran la toxina "killer". Por otra parte, la coexistencia entre las levaduras con fenotipo "neutro" y "sensible" se explica debido a que ninguna de ellas produce la toxina "killer". Sin embargo, la presencia de un solo fenotipo de levadura sugiere que hay factores externos que fueron decisivos en su permanencia durante el proceso fermentativo.

Según Nally et al. (2005), una de las interacciones levadura - levadura del tipo antagónico es el denominado fenómeno "killer", que implica la secreción por parte de ciertas cepas de levadura de una proteína tóxica de baja masa molecular (denominada toxina "killer", a la cual ellas son inmunes) que elimina células denominadas "sensibles", las cuales, pueden ser del mismo o de diferente género. Además, Woods y Bevan (1968) encontraron que existen cepas "neutras" que ni producen la toxina ni son sensibles a ella.

Los estudios de Fleet (2003) indican que, aunque existe más de un tipo de variable que afecta la expresión de los fenotipos "killer" y "sensible", abunda evidencia de que este tipo de interacciones pueden determinar la evolución de las distintas poblaciones de levaduras durante la fermentación. En algunas ocasiones una cepa "killer" de $S$. cerevisiae predomina al final del proceso fermentativo, sugiriendo que la expresión de la toxina le permitió conducir parte de la vinificación.

\section{CONCLUSIONES}

Al determinar el fenotipo "killer" en levaduras productoras de etanol aisladas de chicha de jora del distrito de Moche, región La Libertad, Perú, se concluye que:

1. El fenotipo "killer" representa el 31\% de los cultivos de levadura aislados.

2. El fenotipo "neutro" representa el $47 \%$ de los cultivos de levadura aislados.

3. El fenotipo "sensible" representa el $22 \%$ de los cultivos de levadura aislados.

\section{AGRADECIMIENTOS}

A la Dra. Eva Elizabeth Villanueva Tarazona por su orientación, apoyo, consejos y facilidades brindadas durante la realización y culminación de la presente investigación.

\section{REFERENCIAS BIBLIOGRÁFICAS}

Angulo, L, M L Freire, C Lema, J A Vicente, y E López. 1993. Presencia de levaduras killer durante la fermentación de mostos de O Baixo Miño. Comunicación oral. Congreso: $X V$ Jornadas de viticultura y enología de Tierra de Barros. Zafra: Junta de Extremadura, 215 224.

Bourgeois, C, y J Larpent. 1995. Microbiología Alimentaria, Tomo 2: Fermentación Alimentaria. Zaragoza: Acribia S.A.

Cansado, J, J Velázquez, C Sieiro, P Calo, E Longo, y T Villa. 1992. Role of killer strains of Saccharomyces cerevisiae in spontaneous fermentations. Profiles on biotechnology Vol 71 $\mathrm{N}^{\circ}$ 3. La Coruña: Universidad de Santiago, $127-142$. 
Epifanio, S. 2005. Influencia de la tecnología de vindicación en la microbiología y el desarrollo de la fermentación alcohólica. Tesis Doctoral, Rioja: Universidad de La Rioja.

Farris, G, P Catzeddu, E Berardi, y G Meloni. 1991. Distribuzione del fenotipo killer nei lieviti vinari della Sardegna. Vignevini, 47 - 48.

Fleet, G. 1997. Wine. En Food Microbiology, de M Doyle, 671 - 694. Washington: ASM Press.

Fleet, GH. 2003. Yeast interactions and wine flavour. Int. J. Food Microbiol, 11 - 22.

Fleet, H, y G Heard. 1993. Yeast growth during fermentation. En Wine Microbiology and Biotechonology, de H Fleet y G Heard, 1034 1038. New York: Harwood Academic Publishers.

Hidalgo, P, y M Flores. 1994. Occurrence of the killer character in yeast associated with Spanish winw production. Food Microbiol, $161-167$.

Lafon - Lafourcade, S. 1983. Wine and brandy. En Biotechnology, vol. 5: Food and feed production with microorganisms, de H Rehm y G Reed, 81 - 163. Verlag Chemie: Weinheim.

Lee, B. 2000. Fundamentos de Biotecnología de los Alimentos. Zaragoza: Acribia S.A.

Lema, C. 1995. Ecología de las comunidades de levaduras vínicas en O Baixo Miño. Selección de cepas Saccharomyces cerevisiae. Aplicaciones biotecnológicas y perspectivas. Tesis Doctoral, Vigo: Universidad de Vigo.

Martini, A. 1993. Origin and domestication of the wine yeast Saccharomyces cerevisiae. J. Wine Res.

Mortimer, R, y M Polsinelli. 1999. On the origins of wine yeast. Res. Microbiol, $199-2004$.
Mortimer, R, y M Polsinelli. 1999. On the origins of wine yeast. Res. Microbiol, 199 - 204.

Nally, MC, YP Maturano, F Vázquez, y ME Toro. 2005. Comportamiento de una cepa salvaje de Saccharomyces cerevisiae killer y su isogénica sensible respecto de diferentes fuentes de nitrógeno en cultivos mixtos. Rev. Argent. Microbiol:,73 - 77.

Nguyen, H, y G Panon. 1998. The yeast Metschnikowia pulcherrima has un inhibitory effect against various yeast species. Sciences des Aliments, 515 - 526.

Pretorius, I. 2000. Tailoring wine yeast for the new milenium: novel approaches to the ancient winemaking. Yeast, $675-729$.

Radler, F. 1980. Les facterurs "killer" des levures. Bull I.O.L.V, 546 - 551.

Ribéreau-Gayon, J, E Peynaud, P RibéreauGayon, y P Sudraud.1975. Traité d Oenologie. Sciences et Techniques du vin, vol. 2. Paris: Dunod.

Rodríguez, L, D Abad, J Gomez, J Casanova, y C Lema. 1998. Fenotipo Killer: Distribución en las comarcas de la Ribeira Sacra en las poblaciones de Saccharomyces cerevisiae. Food Technology, 33 - 37.

Shimizu, K. 1993. Killer yeast. En Wine Microbiology and Biotechnology, de H Graham, 243 - 263. Harwood Academic Publishers.

Van Vuuren, HJJ, y CJ Jacobs. 1992. Killer yeast in the wine industry: a review. Am. J. Enol. Vitic, $119-128$.

Vásquez, M. 1979. Determinación para la elaboración de malta de maíz a partir del maíz cancha de Huaraz. Tesis para optar el título de Ingeniero en Industrias Alimentarias, Lima: La Molina. 
Vaughan-Martini, A, y A Martini. 1995. Facts, myths and legends on the prime industrial microorganism.» J. Ind. Microbiol, 514 - 522.

Wickner, RB. 1996. Double-stranded RNA viruses of Saccharomyces cerevisiae.» Microbiol. Rev, 250 - 265.

Woods, D, y A Bevan. 1968. Studies on the nature of the killer factor produced by Saccharomyces cerevisiae. J. Gen. Microbiol, $115-126$.

\section{Correspondencia:}

Cristian Enrrique Polo Zavala

Calle Los Jardines Mz. 7 - Lt. 12

Trujillo-La Libertad, Perú

enrriquemicro@gmail.com 